(C) Religion and Politics Section of the American Political Science Association 2019. Access to this work was provided by the University of Maryland, Baltimore County (UMBC) ScholarWorks@UMBC digital repository on the Maryland Shared Open Access (MD-SOAR) platform.

Please provide feedback

Please support the ScholarWorks@UMBC repository

by emailing scholarworks-group@umbc.edu and

telling us

what having access to this work means to you and why

it's important to you. Thank you. 


\section{American Constitutional Faith and the Politics of Hermeneutics}

Andrew R. Lewis

University of Cincinnati

Andrew.Lewis@uc.edu

William Blake

University of Maryland, Baltimore County

wblake@umbc.edu

Stephen T. Mockabee

University of Cincinnati

Stephen.Mockabee@uc.edu

and

Amanda Friesen

IUPUI

amfriese@iupui.edu

Abstract: As more debates in American politics become constitutional questions, effective citizens must engage in constitutional interpretation. While most Americans venerate the Constitution as a part of a national, civil religion, levels of constitutional knowledge are also very low. In this paper, we analyze how ordinary Americans approach the task of constitutional interpretation. An analysis of two cross-sectional surveys indicates constitutional hermeneutics are a product of both political factors, denominational affiliation, and biblical interpretive preferences. We also present the results of a survey experiment where the manipulation of a clergy's interpretation of a biblical passage affects how respondents interpret both scripture and the Constitution, providing a causal mechanism for learning how to engage in hermeneutics.

Bios:

Andrew R. Lewis is Associate Professor of Political Science at the University of Cincinnati. His research interests include religion and politics and the politics of law. He is the author of The Rights Turn in Conservative Christian Politics: How Abortion Transformed the Culture Wars (Cambridge, 2017). 
William D. Blake is Assistant Professor of Political Science at the University of Maryland, Baltimore County. His research interests include constitutional attitudes and judicial decisionmaking.

Stephen T. Mockabee is Associate Professor of Political Science at the University of Cincinnati. His research interests include political behavior, survey research methodology, and religion and politics. His work has appeared in Political Analysis, Political Research Quarterly, Political Behavior, Journal for the Scientific Study of Religion, and several edited volumes.

Amanda Friesen is Associate Professor of Political Science and a project director in the Center for the Study of Religion \& American Culture at IUPUI. 